\title{
A NOVA LEI DE LICITAÇÕES E CONTRATOS E OS IMPACTOS NA ADMINISTRAÇÃO PÚBLICA
}

\section{ARTIGO ORIGINAL}

SOUZA, Alessandra Milhomem De ${ }^{1}$

SOUZA, Alessandra Milhomem De. A nova lei de licitações e contratos e os impactos na administração pública. Revista Científica Multidisciplinar Núcleo do Conhecimento. Ano 05, Ed. 08, Vol. 06, pp. 126-135. Agosto de 2020. ISSN: 24480959, Link de acesso:https://www.nucleodoconhecimento.com.br/lei/lei-de-licitacoes

\section{RESUMO}

Por meio da realização de pesquisa bibliográfica e documental, a atual produção visa expor as principais transformações que foram propostas para a Lei n. 8.666/1993, que trata dos processos de licitação e contratos, abordando e analisando as mudanças e seus impactos para a Administração Pública, para tal buscou-se utilizar os princípios condutores, bem como a própria legislação, que embasam todo este procedimento. De forma geral, a licitação é um processo obrigatório que a Administração Pública utiliza para a realização de contratos, sejam sobre a aquisição de bens e serviços sejam as alienações. O campo administrativo é uma área que acaba sendo submetida a diversos tipos de alterações que transformam o gestor público em mediador que visa manter a estabilidade entre os objetivos viáveis, os recursos suficientes e a estrutura mais adequada e flexível; essas alterações também acabam por ocasionar a necessidade de mudanças no texto da própria legislação, adequando-a às novas configurações sociais. Nesse sentido, o presente trabalho busca responder a seguinte questão: "Quais os impactos na administração Pública, decorrentes das alterações da lei de Licitações e Contratos propostas no Projeto de Lei 1292/1995?". Portanto, foi possível concluir que este projeto de lei gera mudanças significativas para o processo

\footnotetext{
${ }^{1}$ Graduada (Bacharel) em Ciência Contábeis pela UNIRG - Universidade de Gurupi e Acadêmica do 10ํㅗ́odo do Curso de Direito na UNIRG - Universidade de Gurupi.
} 
licitatório, algumas modificações inovadoras unem-se aos conceitos já dispostos na legislação vigente, exige um planejamento mais concentrado, em prol da eficiência, simplicidade e flexibilidade das licitações, gerando uma relação mais negocial ao processo.

Palavras-chave: Administração Pública, licitação, contratações, alterações, gestor.

\section{INTRODUÇÃO}

Desde 1993, no Brasil, as compras, as contratações, as alienações e as locações realizadas pela administração pública do país são regulamentadas pela lei $\mathrm{n}$. 8.666/93. Aos poucos esta lei ficou significantemente defasada em diversos aspectos técnicos e jurídicos, e não acompanhou a dinâmica da demanda atual de contratações, gerando dificuldades para os gestores públicos, bem como, para os profissionais que atuam nos procedimentos licitatórios e de contratações públicas, em decorrência, principalmente das amarras legislativas e o excesso de burocracia, que estão sujeitos os envolvidos no procedimento licitatório.

Com uma discussão iniciada entre 2015 e 2016, diplomas normativos introduziram inovações para a atualização do modelo de licitações reguladas pela Lei n. 8.666/93, isto fez com que importantes mudanças fossem trabalhadas nos processos licitatórios, em prol de melhores condições para a contratação, a aquisição e a administração de contratos públicos.

Neste sentido, o presente trabalho buscou responder a seguinte problemática: Quais os impactos na administração Pública, decorrentes das alterações da lei de Licitações e Contratos propostas no Projeto de Lei 1292/1995? Objetivando demonstrar de forma detalhadas as especificidades de cada alteração, suas implicações na gestão pública e as motivações para suas aprovações, bem com outros dados que provém deste projeto de lei. 
A temática, Lei de Licitações e Contratos, foi abordada neste estudo, com objetivo de compreender os impactos na administração pública decorrentes do projeto de lei que altera a norma 8.666/93. Para tanto, foi realizada pesquisa bibliográfica e documental.

O presente estudo Justifica-se pelo seu caráter científico em contribuir com a pesquisa jurídica, no cunho profissional, pela possibilidade de propiciar material teórico aos operadores do direito para suas práticas, bem como, no campo social, ao promover à sociedade em geral informações que ajude a população compreender as mudanças legislativas, neste caso, as alterações à lei n. 8.666/93, considerando que as licitações e contratos públicos são de suma importância para a administração pública, e impacta diretamente a vida social e dos cidadãos.

\section{DESENVOLVIMENTO}

\section{AS ALTERAÇÕES DA LEI DE LICITAÇÕES E CONTRATOS E SEUS IMPACTOS NA ADMINISTRAÇÃO PÚBLICA}

Consoante às informações prestadas pela Presidência da República, como disposto no Manual de Gerenciamento de Contratos Administrativos da cidade de Campinas (2020), o projeto de licitações e contratos deverá diminuir disputas e tornar as contratações mais eficientes e lucrativas. Tanto para a Administração Pública, quanto para o coletivo. As modificações na legislação vão desde o alargamento de prazos de contratos à feitura de planos de compras anuais, entre outros, a fim de modernizar a gestão pública (ZUCCO, 2018).

O Projeto de Lei $n^{\circ}$. 1.292/95 prevê mudanças como: pôr fim a obrigatoriedade de a Administração publicar em jornais impressos privados de grande circulação os seus editais de licitação e outros atos administrativos relacionados aos procedimentos das Leis: 8.666/1993 (Lei de Licitações e Contratos), 10.520/2002 (Lei do Pregão), 10.079/2004 (Lei das PPPs) e 12.462/2011 (Lei do RDC). Assim bastando apenas à publicação no Diário Oficial e em sites oficiais do Governo. Cuida-se de analisar ainda que as mudanças atinjam os procedimentos conduzidos pela União, Estados, Distrito Federal e Municípios. 
A Lei no 1.292/95 teve sua versão final votada pelo Plenário da Câmara dos Deputados em 25 de junho de 2019, o seu texto base foi aprovado, e restou a votação dos destaques apensados. Esta nova Lei se tornará um novo estatuto que moldará as normas gerais de Licitação e Contratos para as Administrações Públicas diretas, autárquicas e fundacionais da União, Estados Distrito Federal, Municípios, bem como órgãos dos poderes legislativo e judiciário em todas as esferas.

Após aprovado o Projeto de Lei passará a produzir efeitos a partir de sua publicação, contudo, será estabelecido um prazo de regime de transição de até dois anos. Durante este tempo, a administração pública em geral poderá escolher entre aplicar a lei antiga ou nova, o que trará alguma insegurança jurídica. É impossível que todas as administrações se adequem à nova lei de contratações administrativas imediatamente após sua promulgação.

O projeto de Lei irá se aplicar a alienação e concessão de direito real de uso de bens; compras; locação, concessão e permissão de uso de bens públicos; prestação de serviços; contratações de tecnologia da informação e comunicação (art. 2ํ, I a V e parágrafo único). Determina a não aplicação quando o item possuir valor estimado que supera a receita bruta máxima de enquadramento ou a MPE, já tenha realizado contratos com a Administração Pública no ano calendário superior ao limite de enquadramento (art. $4^{\circ}$, I e II, parágrafos: $1^{\circ}, 2^{\circ}, 3^{\circ}$ ).

Com a entrada em vigor da nova lei, não haverá mais as certas modalidades de licitação, quais sejam: tomada de preços e convite, porém, o projeto contempla uma nova modalidade, denominada de diálogo competitivo, aplicável apenas às contratações de obras, serviços e compras, inspirada nas contratações feitas pela União Europeia e Estados Unidos. O Diálogo competitivo é a modalidade de licitação em que existem diálogos efetuados com licitantes anteriormente escolhidos por meio de critérios objetivos, existindo o desenrolar de uma ou mais alternativas para satisfazer às suas necessidades, devendo os licitantes exibir proposta final depois de findado o diálogo. Com o diálogo a Administração Pública terá a vantagem de conhecer das respostas inovadoras ou mesmo das possibilidades que o mercado 
possui para proporcionar uma contratação mais estratégica, que melhor atender às suas necessidades. (NOHARA, 2019).

Cumpre esclarecer ainda que a Nova Lei de Licitações deixa de determinar a modalidade em razão do valor, mas sim pelo objeto do contrato. Por esse motivo, as modalidades de convite e tomada de preços passam a não mais existir. As modalidades que passam a ter validade a partir da entrada em vigor da nova lei são: Concorrência; Pregão; Leilão; Concurso; e Diálogo competitivo. A concorrência será cabível às contratações de bens e serviços especiais. O pregão tornar-se-á modalidade exigida para contratação de bens ou serviços comuns. O leilão servirá para alienação de bens móveis ou imóveis. Já o concurso irá manter-se aplicável para contratações de serviços técnicos, científicos ou artísticos. E a nova modalidade: diálogo competitivo, que será exigível para contratações de obras, serviços e compras (GANDOLFI, 2019).

A modalidade do contrato proveniente de irregularidades na licitação ou na execução, somente será adotado após a análise de interesse público e de vários aspectos impactantes da melhor solução, artigo 145 e incisos.

O ponto que mais causou debates no trâmite do Projeto de Lei na Câmara dos Deputados foi o aumento dos valores de seguros. Com base na Lei oㅡ 8.666/93, o seguro é opcional sendo correspondente a $5 \%$ do valor, e poderá chegar a até $10 \%$ para contratações mais caras e difíceis. Posteriormente a entrada em vigor da lei, poderá advir seguro (que continua sendo opcional) de até $30 \%$ do valor inicial do contrato, para contratações de mais de 200 milhões de reais. A maior inovação é a cláusula de step in, também em caráter opcional, em que a seguradora, no inadimplemento da contratada, encarrega-se da execução e cumpre inteiramente o contrato ajustado. Refere-se a uma relevante novidade, porém deve-se analisar previamente a cláusula antes de contratar o seguro, se ela não irá encarecer demais o contrato.

Outra novidade é a criação do Portal Nacional de Contratações Públicas, que será formado por representantes de diversos entes federativos, constituindo uma Rede 
Nacional de Contratações Públicas. Será visto como o sítio eletrônico das licitações. Neste Portal será feito o registro cadastral unificado (mesmo havendo a extinção da modalidade registro de preços, sendo exequível à Administração fazer licitações unicamente com licitantes cadastrados). Observa-se que pelo PNPC existirá a possibilidade de divulgação do contrato e de seus aditamentos, equivalendo, inclusive, a publicação no portal como condição de eficácia do contrato.

Ademais, o projeto de lei da nova lei de licitações e contratos, converterá a inversão de fases em regra. A Inversão de fases é a denominação que se dá à feitura do certame em que o julgamento é anterior à habilitação. O método herdado pela Lei $n$ 8.666/93 prevê as sequentes fases da licitação: edital, habilitação, julgamento, homologação e adjudicação.

Uma vez razoável, o orçamento de recrutamento estimado pode ser confidencial e será tornado público após o julgamento da proposta. No entanto, essa confidencialidade não afetará os órgãos de controle interno e externo. O objetivo de um orçamento confidencial é manter a empresa sem conhecimento do valor estimado do recrutamento, pois se o fizer, poderá fazer recomendações próximas do que a administração pretende gastar (mesmo que alguns concorrentes possam oferecer preços mais baratos). Portanto, é compreensível que o sigilo das estimativas orçamentárias proporcione à administração contratos mais favoráveis.

Após a mudança, a nova lei costuma estipular que as comissões de licitação não sejam compostas por pelo menos três servidores, mas por licitações diárias. Trata-se de um sistema mais próximo da camada inferior, o que significa que o poder é delegado a agentes com as devidas qualificações, e a menos que haja suporte Além da ajuda da equipe, ele deve ser funcionário.

Outra alteração relacionada é o aumento do valor do contrato que pode ser firmado diretamente, aumentando o contrato de serviço e compra para 50.000 reais e 100.000 reais para a realização de serviços de engenharia automotiva e engenharia ou manutenção. De acordo com o disposto no artigo $8^{\circ}$, em vez de Pregoero e dos membros da Comissão de Licitação, designar um agente contratante. 
Adicionalmente, nos termos do artigo $10 .^{\circ}$ do seu direito público, as autoridades e funcionários que participem no processo de licitação e nos contratos serão representados pelo direito público. O processo licitatório divide-se nas seguintes etapas: preparação, editais de licitação, apresentação de propostas e licitações, julgamento, habilitações, recursos e certificação (art. 17, arts. 1ํa $7^{\circ}$ ).

O artigo 20 determina que as audiências públicas serão realizadas durante o processo licitatório com base na atuação e sugestões dos interessados, portanto, o artigo 23 reconhece o sigilo das estimativas orçamentárias e as torna públicas na fase de licitação.

Para a prestação de obras, serviços e um grande número de pessoas, os vencedores devem ser obrigados a desenvolver um plano de integridade, que deve ser implementado de acordo com as leis e regulamentos externos e internos (artigo 24, parágrafo $\left.4^{\circ}\right)$. Portanto, o contrato deve estabelecer um índice de ajuste vinculando a data prevista do orçamento (Artigo 24, parágrafo 7).

Para cidades e vilas com uma população de até 50.000 habitantes, uma margem preferencial de até $10 \%$ pode ser fixada, Artigo 26, parágrafo 4 . Neste sentido, a concorrência e o horário de negociação partilham uma fase comum, não se alterando a modalidade de programação do horário em curso, sendo, no entanto, vedada a utilização do horário para a prestação de serviços técnicos essencialmente de conhecimento, artigo 28. e alíneas individuais.

O diálogo competitivo limita-se a quem detém tecnologia ou inovação tecnológica, necessita de adequar a solução, não podendo a autoridade competente definir com precisão as especificações técnicas (artigo 31..-, incisos I e II). Os critérios de análise das propostas são o menor preço, o maior desconto, a melhor tecnologia e preço, o maior lance na situação do leilão e o maior retorno econômico (artigo 32).

Os métodos de execução dos determinados projetos e serviços são contratos de preço unitário, contratos de preço global, geral, contratos de tarefa, contratos abrangentes, semi-integrados (exceto para projetos, serviços e materiais com valor 
superior a 10 milhões de reais), a prestação de serviços relacionados e Fornecido (Artigo 44). É proibida a realização de projetos e serviços sem execução do projeto, exceto para aqueles que utilizem um sistema abrangente de cumprimento de

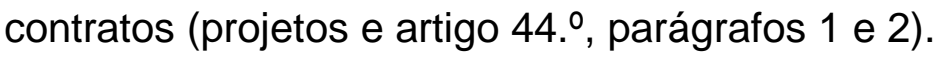

É vedada a disputa no modo fechado quando o critério de julgamento for por menor preço ou maior desconto, conforme o artigo 54, incisos I e II, parágrafo primeiro. Do mesmo modo que haverá a modalidade Concorrência para obras, serviços especiais e serviços comuns de engenharia, por meio do rito comum do atual pregão como procedimento, e aplicando como modo de disputa aberto quando adotado o critério de julgamento pelo menor preço ou maior desconto (artigo 54, parágrafo $1^{\circ}$ ).

No julgamento da licitação por técnica e preço, é impedido a disputa de modo aberto segundo o artigo 54, parágrafo $2^{\circ}$. A desclassificação de propostas no caso de obras e serviços de engenharia não pode ser realizado quando inferiores a $75 \%$ do valor orçado pela Administração, prevendo a garantia adicional em propostas inferiores a $85 \%$ (artigo 57, parágrafo 4ํㅡㄹ e $5^{\circ}$ ).

Se a licitação for inferior a $R \$ 100.000,00$, poderá ser utilizada para serviços de engenharia, engenharia e conserto de veículos, se a licitação for inferior a $R \$$ $50.000,00$ poderá ser utilizada para outros itens (art. 73, incisos I e II). Por outro lado, o sistema de registo de preços pode ser utilizado para celebrar contratos de bens e serviços, incluindo obras e serviços de engenharia (artigo 78.ํ, n.ำ 5 , e artigo 81.. , n.. s 1 e 11).

Será criado um registo que comprove o cumprimento da obrigação e referência à sua execução na execução do contrato para que os incentivos aos licitantes possam ser implementados (artigo 84. , n.ㅇs 3 e 4). Quando o valor estimado é de 100 milhões de dólares americanos, o maior requisito de garantia contratual para obras, serviços e fornecimentos é de $10 \%$, e quando o preço é superior a esse preço, é necessário um depósito de $20 \%$. Por fim, é importante para obras e serviços de engenharia $A$ necessidade de sexo chega a $30 \%$. digital. 
A partir do julgamento do menor preço ou do maior desconto, o menor tempo entre o anúncio do edital e a exibição da mercadoria sugerida é de 8 dias úteis, e as demais opções são de 15 dias úteis. No que se refere aos serviços e obras, os serviços gerais, obras e obras custam 10 dias úteis com preço inferior ou maior desconto, e para serviços especiais, obras e obras são 25 dias úteis segundo a norma anterior. Anteriormente, abrangia 60 dias úteis no sistema integral de execução de contratos, 35 dias úteis no sistema semi-integrado de execução de contratos e demais condições, inclusive tecnologia e preços (art. 53, incisos I a IV).

Para um grande número de projetos, serviços e suprimentos contratados, a lei estipula que o anúncio deve notificar o licitante vencedor da obrigação de determinar o plano de integridade no prazo de seis (seis) meses após a conclusão do contrato, de acordo com os regulamentos da agência de controle.

O artigo 105 estipula que os contratos de serviço e fornecimento contínuo podem ser prorrogados continuamente por um período máximo de dez anos. No projeto, os recursos financeiros necessários devem ser vinculados à conta do Art. 113 da Seção II, antes do envio da ordem de serviço de cada etapa para pagamento da etapa a ser executada.

Em caso de atraso no pagamento superior a dois meses (calculado a partir da data de emissão indicada no artigo 135.. , n.ำ 2, n.. 2, da fatura), pode ser utilizada a modalidade de contratação. O pagamento está atrasado por mais de 45 dias, você pode operar com a taxa de juros prescrita e $0,2 \%$ de juros mensais. Pode haver meios alternativos de prevenção e solução de controvérsias, especialmente solução, mediação e arbitragem (Artigo 149).

Os recursos administrativos para julgamento da proposta, habilitação, revogação ou cancelamento serão de três dias úteis, sendo que os recursos administrativos utilizados para o julgamento serão acompanhados da manifestação de intenção (art. 163, inciso 1 , § $1^{\circ}$, item 1 e $\S 1^{\circ}$ ) Item 2 . De acordo com o Artigo 173, incisos e parágrafos, foi estabelecido um comitê de gestão de compras públicas incluindo contratos municipais. 
O projeto é inovador em vários aspectos, incorpora precedentes judiciais em diversos assuntos e está relacionado principalmente ao direito administrativo contemporâneo. Houve progresso nas possibilidades de mediação, solução de controvérsias, comitês de arbitragem e programas de integridade da administração pública.

\section{METODOLOGIA}

O presente estudo foi desenvolvido por meio de pesquisa bibliográfica com levantamento de dados em doutrinas, normas legais, artigos, revistas, jornais, sites, tendo como fundamento teórico, escritores e pesquisadores da área de direito administrativo com notório saber sobre o assunto pesquisado, em busca da identificação dos conceitos a respeito da Administração Pública, licitações e contratos. Foram utilizados ainda documentos legais, como: a Constituição Federal de 1988, a atual lei 8.666/1993 (Lei de licitações e contratos), também a lei 10.520/02 (Lei do pregão) e dispositivos da lei 12.462/2011 (Lei do RDC), a lei 1.292/95, dentre outras legislações que embasam o processo licitatório na gestão pública.

\section{CONSIDERAÇÕES FINAIS}

Em virtude das informações que foram exposta ao longo desta produção, temos que os processos que que englobam compras realizadas na Administração Pública são tidos de maneira minuciosa e complexa, na qual necessita-se que os envolvidos nestes procedimentos possuam compreensão aprofundada da questão, de forma a não ser esquecido que a legitimidade e a transparência são princípios importantes e necessários para as ações administrativas.

Com isso, o processo de licitação promoverá uma maior observação dos princípios constitucionais de isonomia, garantindo que a proposta escolhida seja àquela que conseguirá atender os interesses da realização dos serviço, ao passo em que proporcione maiores e melhores vantagens para a administração, evidenciando a importância de todas as áreas governamentais estarem adequadas a todas estas disposições normativas quando forem realizar novas contratações. Isto nos mostra a importância que este procedimento possui para a atual sociedade, sendo importante, 
também, compreender as alterações transcorridas na legislação para que o dever legal seja cumprido.

Face ao exposto, a nova poderá trazer alterações importantes aos procedimentos de concurso, e procurará sanar as lacunas jurídicas dos contratos públicos e dos contratos na legislação em vigor, de forma a criar melhores condições para a contratação e gestão dos contratos públicos. Obviamente, o projeto de lei visa melhorar a eficiência das licitações, tornando-as mais simples e flexíveis, também traz mais consenso para o ambiente de licitação por meio de mais consenso e relações negociadas. O país colherá muitos benefícios com a simplificação das licitações, os trâmites serão mais ágeis e a engenharia, os serviços e as mercadorias terão melhor qualidade e eficiência

Desta maneira, em relação ao objetivo proposto inicialmente, a atual produção acredita ter cumprido seu propósito de expor as alterações que serão implementadas na Lei de Licitações e Contratos, Lei n. 8.666/95, ainda assim, temos que ter em mente que a realização de novos estudos e análises é de suma importância para que os pormenores de cada transformação seja determinados e compreendido mais amplamente, bem como, tenha-se a observação e análise das alterações que ocorrerão em processos licitatórios por consequência, o que evidencia que este tema ainda não foi totalmente esgotado.

\section{REFERÊNCIAS}

ACKEL, Pedro Teixeira Leite; CHAVES, Julio Cesar. Impactos da nova lei para mudanças nas licitações e contratos públicos. Revista Jus Navigandi, ISSN 15184862, Teresina, ano 24, n. 5908, 4 set. 2019 D Disponível em: https://jus.com.br/artigos/75536. Acesso em: 3 jun. 2020.

ALVES, Erick. Mudanças na Lei 8666, Lei do Pregão e outras leis. Site: Direção Concursos, 2019. Disponível em: https://www.direcaoconcursos.com.br /artigos/medida-provisoria-altera-lei-8666-lei-do-pregao-e-outras-leis/ Acessado em: 28 mar. 2020. 
BRASIL. Constituição (1988). Constituição da República Federativa do Brasil. Brasília, DF: Senado Federal. . Lei oㅡ 8.666, de 21 de junho de 1993. Lei Licitações e Contratos. Brasília, DF, Senado Federal, 1993.

CARVALHO, Matheus. Manual de Direito Administrativo. 2 ed. rev., ampliada e atualizada. Salvador: Juspodivm, 2015.

CARVALHO FILHO, José dos Santos. Manual de direito administrativo. 27. ed. rev., ampl. e atual. São Paulo: Atlas, 2014.

DI PIETRO. Maria Sylvia Zanella. Direito administrativo. 27. ed. São Paulo: Atlas, 2014.

GANDOLFI, Paula. Entendendo a Nova Lei de Licitações. Site: RCC Soluções em Licitações, 2019. Disponível em: https://www.rcc.com.br/blog/ente ndendo-a-nova-leide-licitacoes/. Acessado em: 28 mar.2020.

GOMES, Fábio Bellote. Elementos de Direito Administrativo. 2. ed. São Paulo: Saraiva, 2012.

JUSTEN FILHO, Marçal. Comentários à lei de licitações e contratos administrativos. 16 ed. rev., atual. e ampl. São Paulo: Editora Revista dos Tribunais, 2014.

JUSTEN FILHO, Marçal. Comentários à Lei de Licitações e contratos administrativos. 13. ed. São Paulo: Dialética, 2009.

LIMA, Alberto de Barros. O que muda na nova lei de licitação. Revista Jus Navigandi, ISSN 1518-4862, Teresina, ano 24, n. 5935, 1 out. 2019. Disponível em: https://jus.com.br/artigos/75497. Acesso em: 3 jun. 2020.

NOHARA, Irene. 8 Principais Mudanças com a Nova Lei de Licitações e Contratos. Site: Direito Administrativo, 2019. Disponível em: https://direitoadm 
.com.br/8-principais-mudancas-com-a-nova-lei-de-licitacoes-e-contratos/

Acessado em: 28 mar. 2020.

ZUCCO, Fabiano. O que Você Precisa Saber Agora Sobre a Nova Lei de Licitações. Site: RCC Solução em Licitações, 2018. Disponível em: https://ww w.rcc.com.br/blog/nova-lei-de-licitacoes/. Acessado em: 28 mar. 2020.

Enviado: Agosto, 2020.

Aprovado: Agosto, 2020. 